\title{
J. J. Rousseau E O Processo Educacional De Formação Do Homem Na Sociedade
}

\section{J. J. Rousseau And Educational Process Of The Man In Society}

Jorge Marques Pontes

Mestrando em Políticas Públicas na Universidade de Mogi das Cruzes - UMC, Graduado em Filosofia, Especialista em Gestão Pública e Servidor da Fundação Jorge Duprat Figueiredo de Segurança e Medicina no Trabalho -FUNDACENTRO. E-mail: jorge.pontes@live.com.

\section{Resumo}

O artigo desenvolve uma reflexão sobre a educação como um processo de formação do homem na sociedade a partir da concepção filosófica de Jean-Jacques Rousseau extraída de sua obra Emílio ou Da Educação, buscando discutir o conceito de educação nas dimensões da ética e da política frente a nossa contemporaneidade através do confronto das idéias do filósofo genebrino com outros autores. Concluindo que, mesmo desprezando a dimensão antropológica da "educação negativa" de cunho não diretivo defendida pelo autor e as atualizações modernas desse pensamento como a Escola de Summerhill, prevalece uma dimensão subjetiva que, para que haja um bom desenvolvimento do homem, necessita contar com a contribuição da filosofia e da sociologia, estimulando-o a refletir sobre ele mesmo e a sociedade em que vive.

Palavras-chave: Filosofia da Educação. Pedagogia. Educação. Iluminismo. Política.

\begin{abstract}
The article develops a reflection about education as a training process of the man to live in the society based on the philosophical conception of Jean-Jacques Rousseau extracted from his work. Emile, or On Education. Through the confrontation of the ideas of the Genevan philosopher with other authors, we discuss the concept of education in the dimensions of ethics and political at our contemporary world. Concluding that, even disregarding the anthropological dimension of "negative education" of non-directive nature beld by the author and the modern updates, prevails a subjective dimension, and consequently for the development of the man, we need count with the contribution of philosophy and sociology, encouraging bim to reflect about bimself and about the society be lives.
\end{abstract}

Keywords: Philosophy of Education. Pedagogy. Education. Enlightenment. Politics. 


\section{Introdução}

\section{Quem Foi Jean-Jacques Rousseau?}

Um dos mais importantes filósofos do Iluminismo, o filósofo político, educador e ensaísta, Jean-Jacques Rousseau nasceu em Genebra, Suíça, em 28 de junho de 1712. Sua mãe morreu no parto e ele não teve qualquer educação formal até os 16 anos, exceto sua própria leitura das Vidas de Plutarco e uma coleção de sermões calvinistas. Tornou-se o protegido de Madame Louise-Éléanore de la Tour du Pil, a baronesa de Warens.

[...] encontrou refúgio em Les Charmettes, nas proximidades de Chambéry, junto de madame de Warens, que the foi mãe, amiga e amante. "Uma mulher toda ternura e docura", como ele a recorda, que the possibilitou estudar e se instruir, sem distrações, longe do tumulto da cidade. Escreve Rousseau: Uma casa isolada sobre o declive de um vale foi nosso refúgio: lá, durante quatro ou cinco anos, desfrutei de um século de vida e felicidade pura e plena, que oculta com seu esplendor tudo aquilo que a minha situação presente tem de horrivel (REALE; ANTISIERI, 2005, p.277).

Aos 30 anos colaborou com a enciclopédia de Diderot e D’Alembert no verbete Música e aos 38 anos conquistou o prêmio da academia de Dijon com seu Discurso

\footnotetext{
${ }^{1}$ Divergências de opinião entre Rousseau e Hume motivaram o retorno do genebrino à França. Segundo Russell (1945, p. 673) A briga entre Hume e Rousseau é simbólica: Rousseau era louco, mas influente, Hume era sã, mas não tinha seguidores. Empiristas britânicos posteriormente rejeitaram seu ceticismo sem refutá-lo;
}

sobre as ciências $e$ as artes. No ano de 1762, Rousseau começou a ser perseguido na França, pois suas obras foram consideradas uma afronta aos costumes morais e religiosos, o que o levou a se refugiar na cidade suíça de Neuchâtel. Em 1765, foi morar na Inglaterra a convite do filósofo escocês David Hume ${ }^{1}$. Pouco tempo depois, retornou à França, velho e cansado, doente e deprimido, Rousseau aceitou o convite do marquês de Girardin e hospedou-se no castelo de Ermenonville onde passou os últimos meses de vida em clima de relativa tranqüilidade, casando-se com Thérèse Levasseur no ano de 1767. Aos 66 anos, atingido por insolação durante um passeio a tarde, veio a falecer em 2 de julho de 1778 .

\section{Os Princípios Filosóficos Da Educação Iluminista De Rousseau}

"Que se destine meu aluno a carreira militar, a eclesiástica ou advocacia, pouco me importa. Antes da vocação dos pais, a natureza o chama para a vida humana, viver é o ofício que lhe quero ensinar [...]" (Rousseau, 1995, p. 15).

A obra "Emílio ou Da Educação", sobre a qual exerceremos a nossa reflexão, é um ensaio pedagógico que une política, educação e ética sob a forma de romance e nele o autor procura traçar as linhas gerais que deveriam ser seguidas

Rousseau e seus seguidores concordaram com Hume no fato de que nenhuma crença é baseada na razão, mas colocavam o coração acima da razão, e isto permitiu-lhes chegar a convicções muito diferentes daquelas que Hume tinha na prática. 
com o objetivo de fazer da criança um adulto bom ou mais especificamente, evitar que a criança se torne má, já que o pressuposto básico do autor é a crença na bondade natural do homem.

Aliás, ressaltamos que isto é próprio do pensamento deste filósofo iluminista, sempre permeado pela ideologia que prega o estado de natureza habitado pelo bom selvagem, ou seja, o homem inicialmente bom que será corrompido pela criação da propriedade e das relações sociais (civilização). E acrescentamos que em sua obra Do Contrato Social, em que o autor apresenta a preocupação de construir uma sociedade justa para que este homem viva foi publicada em 1762, um ano antes da que analisamos agora.

Rousseau (1995, p. 5) no prefácio da obra em questão cita uma bela frase de Sêneca ${ }^{2}$ como epígrafe que reflete este primeiro princípio da bondade inata, dizendo: "Sofremos de uma doença curável, e, nascidos para o bem, somos ajudados pela natureza em nos querendo corrigir".

Outro princípio filosófico do pensamento rousseauniano em sua obra consiste em atribuir à civilização (a doença curável) a responsabilidade pela origem do mal. Conseqüentemente, os objetivos da educação, para Rousseau, comportam dois aspectos

\footnotetext{
${ }^{2}$ Lucio Aneu Sêneca nasceu em Córdoba, na Espanha, entre o fim da era pagã e o início da era cristã. Em Roma, participou ativamente e com sucesso da vida política. Condenado por Nero ao suicídio em 65 d.C.
}

correlacionados a estes princípios: a) o desenvolvimento das potencialidades naturais da criança e; b) seu afastamento dos males sociais (civilização).

Destacamos que de início ele deixa claro suas intenções com o livro dizendo:

Falarei pouco da importância de uma boa educação; nem me deterei tampouco em provar que a que se pratica é ma; mil outros o fizeram antes de mim, e não me agrada encher um livro com coisas que todo mundo sabe. Observarei tão-somente que desde sempre todos se opõem ao estabelecido, sem que ninguém pense em propor coisa melhor (ROUSSEAU, 1995, p. 5).

No século XVIII, existiam muitas teses sobre a educação, muita coisa já havia sido dita e escrita, todavia, na visão de Rousseau, poucos apresentavam propostas. Era a crítica pela crítica. Ele se propõe uma reforma na educação, uma nova visão e começa dividindo a existência em cinco fases: 1) Lactância até dois anos; 2) infância de dois a doze; 3) adolescência de doze a quinze; 4) mocidade de quinze a vinte e; 5) o início da vida adulta de vinte a vinte e cinco anos. Dos cincos livros da obra, os quatro primeiros tratam da educação do menino Emílio e último da educação da menina, sugestivamente chamada, Sofia.

A obra é inspiradora da Escola Nova e Heinrich Pestalozzi ${ }^{3}$, e se contrapõe a visão

\footnotetext{
3 Escola Nova, "Escola Ativa" ou "Escola Progressiva" são os nomes dados a um movimento de renovação do ensino que foi especialmente forte na Europa, na América e no Brasil, na primeira metade do século XX. Entre inspiradores da Escola Nova, além de Jean-Jacques
} 
elitista da educação como privilégio, afirmando ser um direito de todos. Estabeleceu uma crítica a pedagogia jesuíta rígida, punitiva e mera transmissora hierárquica de conhecimentos memorizados, que tratava a criança como um adulto em miniatura.

\section{Quem é Emílio?}

O jovem Emílio, filho de um homem rico, é educado por um preceptor no convívio com a natureza protegido dos constrangimentos sociais. Emilio é o representante da espécie humana em seu potencial de virtude, educado para viver bem consigo, com sua futura companheira Sofia e com os outros, em uma sociedade livre e democrática.

Rousseau entendia a infância como uma forma particular de ser humano diferente da idade adulta. $\mathrm{O}$ aprendizado era conduzido pelos interesses do próprio aprendiz, em uma educação de dificuldades progressivas, lúdicas e interativas que evoluíam naturalmente do sentido ao espírito, em uma seqüência natural de aprendizado da vida, sem sobressaltos ou imposições.

Tudo é certo em saindo das mãos do Autor das coisas, tudo degenera nas mãos do homem. Ele obriga uma terra a nutrir as produções de outra, uma árvore a dar

Rousseau (1712-1778), estão Heinrich Pestalozzi (1746-1827) e Freidrich Fröebel (1782-1852). Na América podemos como grande expoente o filósofo John Dewey (1859-1952). As idéias do movimento foram introduzidas no Brasil em 1882 por 1882 por Rui Barbosa (1849-1923). No século XX, após a divulgação do Manifesto dos Pioneiros da Educação Nova, de 1932. Alguns nomes foram destaque, entre eles Lourenço Filho (1897-1970) e Anísio Teixeira (1900-1971).

${ }^{4}$ Thomas Hobbes nasceu em Malmesbury, em 1588. Bem cedo frutos de outra; mistura e confunde os climas, as estações; mutila seu cão, seu cavalo, seu escravo; transtorna tudo, desfigura tudo; ama a deformidade, os monstros; não quer nada como o fez a natureza, nem mesmo o homem [‥] (ROUSSEAU, 1995, p. 9).

Se por um lado ele identificava as especificidades do ser infantil, por outro, projetava o homem do amanhã delimitando claramente a fronteira entre o homem da natureza e o homem civil (ser social). Este é o motivo dominante das obras de Rousseau, ou seja, os bens que a humanidade crê ter adquirido, os tesouros do saber, da arte, da vida requintada não contribuem para felicidade e a virtude do homem, ao contrário, serve para o afastar da sua origem e o extraviar em sua natureza. Para ele a vida social se rege muito mais pelos vícios do que pelas virtudes; pois é o egoísmo, a vaidade e a necessidade de domínio que governam as relações entre os homens. Essa teoria do estado de natureza é que dá origem a uma de suas idéias mais difundidas: o homem nasce naturalmente bom, a sociedade é que o corrompe.

Rousseau herda essa concepção de estado natural de filósofos como Thomas Hobbes $^{4}$, mas faz uma leitura diferente deste conceito, inversa por assim dizer, conferindo-lhe um novo significado. Para esclarecer melhor a diferença entre estes dois conceitos Hobbes

aprendeu o grego e o latim, e muitos de seus escritos (suas obrasprimas) foram redigidos em língua latina. Completando os estudos superiores em Oxford, a partir de 1608 torna-se preceptor do Lord Hardwick, conde de Devonshire. Fez diversas viagens no continente e, de 1640 até 1651, durante a ditadura de Cromwell, viveu voluntariamente no exílio em Paris, onde, em 1646 até 1648, foi professor de matemática do futuro rei Charles II. Morreu em 1679 (RUSSELL, 1945). 
nutria uma profunda aversão ao filósofo estagirita, Aristóteles ${ }^{5}$. Este último acreditava que o homem era um animal político e que tinha por natureza a propensão de viver em uma sociedade politicamente estruturada, assim como os animais, a exemplo das abelhas e das formigas.

A filosofia de Hobbes (REALE; ANTISIERI, 2005, p.82) refuta totalmente esta visão ao alegar que o homem não é de modo algum ligado aos outros homens por um consenso espontâneo como os animais, visto que estes últimos se baseiam em um "apetite natural". Desta forma, dois princípios defendidos por este filósofo em suas obras nos servem como contraponto a Rousseau. O primeiro é que ele considerava que os animais não percebem defeitos em sua sociedade, ao passo que o homem os percebe, querendo introduzir continuas novidades, que constituem causas de discórdias e guerras. Segundo, os animais não se censuram uns aos outros, ao passo que os homens sim. Considerando estes princípios, teríamos uma luta de todos contra todos no estado de natureza, o que preconiza a necessidade do estabelecimento de um Estado.

Como ilustração, apresentamos a um conto de Assis (1994) onde o personagem cônego Vargas em uma conferência anuncia que teria dado um regime social às aranhas. Ele inicia sua preleção da seguinte forma:

${ }^{5}$ Aristóteles 384-322 a.C ., filho de Nicômacos e de Faistis,nasceu

\begin{abstract}
Senhores, vou assombrar-vos, como teria assombrado a Aristóteles, se lhe perguntasse: Credes que se possa dar um regime social às aranbas? Aristóteles responderia negativamente, com vós todos, porque é impossivel crer que jamais se chegasse a organizar socialmente esse articulado arisco, solitário, apenas disposto ao trabalho, e dificilmente ao amor (ASSIS, 1994).
\end{abstract}

Inicialmente, de maneira irônica, o autor reflete a crítica de Hobbes a Aristóteles. E ressaltamos o fato de que o filósofo grego acreditava em uma sociedade estruturada entre os animais; à medida que o inglês o criticava, como vimos nos parágrafos anteriores. Assis (1994) expressa sua ironia através de um antropomorfismo, ou seja, uma visão de mundo que, buscando a compreensão da realidade circundante, atribui características e comportamentos típicos da condição humana aos seres vivos irracionais. Neste caso, as aranhas são a representação dos homens na nossa sociedade. Em mais um trecho transcrito abaixo, ele mostra as aranhas (os homens) criticando defeitos em sua sociedade, pois se decidiu que haveria de existir um governo e assim necessitaria de uma eleição, contudo, logo que foi realizado o pleito, um fato ocorreu: A eleição fez-se a princípio com muita regularidade; mas, logo depois, um dos legisladores declarou que ela fora viciada, por terem entrado no saco duas bolas com o nome do mesmo candidato. (ASSIS, 1994).

Várias são as situações que ocorrem em Estagira. (LAÊRTIOS, 2008, p. 129) 
durante as eleições, até que finalmente, depois de muitas emendas às leis feitas, chega-se ao consenso - não definitivo, claro - de preparar-se um novo saco de escrutínio onde seriam colocadas as bolas e, sendo decidido que assim se sucederia até que a sabedoria os socorresse. $\mathrm{O}$ autor ilustra bem a posição hobbesiana em relação ao homem, mas também - mesmo não sendo esta a intenção - mostramos o homem tentando mudar algo que é natural (as aranhas).

\section{Retomando o pensamento} rousseauniano, para o filósofo genebrino, em vez de uma luta de todos contra todos; o homem tem uma garantia natural de independência e total desinteresse pelos bens alheios. Este enfoque esta representado na máxima proferida por ele em outra de suas obras, Do Contrato Social, onde afirma que o homem: "No estado de natureza, onde tudo é comum, nada devo a quem nada prometi, e não reconheço a outrem o que me é inútil” (ROUSSEAU, 2008, p. 55).

No seu livro, "O Discurso sobre a Origem e os Fundamentos das Desigualdades entre os Homens", ele apresenta o ser humano em seu estado de natureza, como um ser doce e meigo, distante da estupidez dos brutos e das funestas luzes da civilização. $O$ homem neste estado é compelido, tanto pelos instintos, quanto pela razão, a defender-se do mal que o assola. Eis um ponto em comum entre Hobbes e Rousseau, ambos acreditavam nos instintos como um desejo de evitar a guerra continua, para salvar a vida, e a necessidade de conseguir aquilo que é necessário para a sobrevivência. Contudo, vemos também o ponto divergente no uso da razão, por Hobbes entendida não como um valor em si, mas como instrumento capaz de realizar aqueles desejos de fundo. Ao ponto que para Rousseau, a razão é vista como um valor em si, capaz de levar os homens a um consenso permeado por uma piedade natural que o impede de fazer mal a outrem. A origem deste conceito pode estar no que Rousseau (apud REALE; ANTISIERI, 2005, p.281) chamava de Bom Selvagem: Os selvagens não são precisamente maus, porque não sabem o que seja ser bons; não é o aumento das luzes nem o freio da lei que lhes impede de fazer o mal, mas a calma das paixões e a ignorância do vício.

Entretanto, a criação da propriedade privada corrompe esta pureza no homem, destrói o estado natural. Pois, o domínio dos bens desencadeia um processo de desigualdade que gera a violência e a corrupção moral da humanidade.

\section{Estado De Natureza E A Educação}

Como evitar isso? Como formar um homem que conserve suas virtudes, sua liberdade, sua autonomia e sua compaixão frente às desigualdades criadas pelo próprio homem? E mais, a educação pode determinar a natureza do homem? 
Saindo de minhas mãos, ele não será, concordo, nem magistrado, nem soldado, nem padre; será primeiramente um homem. Tudo o que um homem deve ser, ele o saberá, se necessário, tão bem quanto quem quer que seja; e por mais que o destino o faça mudar de situação, ele estará sempre em seu lugar (ROUSSEAU, 1995, p. 15).

Se for verdade que o homem nasce bom e a civilização torna o mundo e o homem artificial, corrompe o ambiente natural e altera o equilíbrio ecológico, então a reforma da educação no sentido de reverter uma desnaturação do ser pode se tornar um instrumento adequado para criar uma humanidade melhor.

Rousseau (1995, pp. 14-15) tinha um apreço pela obra de Platão, $A$ República, Ele a considerava não como um livro sobre política "como pensam os que julgam livros pelo título", mas o mais belo tratado sobre educação que jamais se escreveu e aconselhava a sua leitura àqueles que queriam ter uma idéia sobre educação pública. Em sua visão "Platão não fez senão depurar o coração do homem", à medida que Licurgo - um conhecido legislador “desnaturou-o". A explicação é que Rousseau, assim como o filósofo grego, acreditava que o homem era educado para desempenhar um papel na sociedade. Ele pregava que o homem para ser alguma coisa era "preciso agir como se fala" e estar sempre "decidido acerca do partido a tomar". Isto pede uma autonomia natural para refletir sobre o que se quer, sendo bom para si e para os outros. E ele (ROUSSEAU, 1995, p. 15) via isto como uma consequência, pois: "Na ordem natural, sendo os homens todos iguais, sua vocação comum é o estado de homem; e quem quer seja bem educado para esse, não pode desempenhar-se mal dos que com esse se relacionam".

A educação da sua época recebia uma crítica ferrenha da parte dele, chegando ao ponto de dizer que não encarava "como uma instituição pública esses estabelecimentos ridículos a que chamam colégios" (ROUSSEAU, 1995, p. 14). Entretanto, o homem não instruído desde cedo, segundo Rousseau, sofre com a pressão social que manipula a mente do indivíduo desde o nascimento, diz ele:

\footnotetext{
No estado em que já se encontram as coisas, um homem abandonado a si mesmo, desde o nascimento, entre os demais, seria o mais desfigurado de todos. Os preconceitos, a autoridade, a necessidade, o exemplo, todas as instituições sociais em que nos achamos submersos abafariam nele a natureza e nada poriam no lugar dela. Ela seria como um arbusto que o acaso fez. nascer no meio do caminho e que os passantes logo farão morrer, nele batendo de todos os lados e dobrando-o em todos os sentidos (ROUSSEAU, 1995, p. 9).
}

$\mathrm{O}$ autor defende que o homem altera a natureza das coisas, forçando terrenos a nutrir produtos próprios de outros; árvores a dar frutos de outras; mistura e confunde os climas; os elementos; as estações; mutila os animais; ou seja, não quer nada da forma que foi feita pela natureza, nem mesmo o próprio homem. 
Para ele, uma reforma da educação seria a saída para este dilema, pois todas as cognições nascem da relação com o ambiente. Logo, é a educação que forma as mentes. Sendo assim, a natureza educa os sentidos, o ensino a mente e a experiência o comportamento, estes seriam nossos mestres, “[...] porque nossos verdadeiros mestres são a experiência e o sentimento" (ROUSSEAU, 1995, P. 191).

\begin{abstract}
Nascemos fracos, precisamos de força; nascemos desprovidos de tudo, temos necessidade de assistência; nascemos estúpidos, precisamos de juízo, tudo que não temos ao nascer, de que precisamos adultos, nos é dado pela educação [...] Essa educação nos vem da natureza, ou dos homens ou das coisas. $O$ desenvolvimento interno de nossas faculdades e de nossos órgãos é a educação da natureza; o uso que nos ensinam a fazer desse desenvolvimento é a educação dos homens; e o ganho de nossa própria experiência sobre os objetos que nos afetam é a educação das coisas. Cada um de nós é, portanto formado por três espécies de mestres (ROUSSEAU, 1995, p. 10).
\end{abstract}

Contudo, que tipo de educação é essa que o autor nos apresenta? Qual o papel do professor? A criança em Rousseau é compreendida como um ser constituído por uma única e invariável estrutura interna por natureza - ou seja, por definição. Não há circunscrição histórica ou geográfica que possa alterar esta perspectiva. A criança relatada por Rousseau é compreendida como um dado imanente, que pode ser compreendido de antemão como se fosse uma essência. Emílio é um menino educado segundo as leis da natureza, afastado dos seus conterrâneos, em um tranqüilo vilarejo no campo, em contato direto com o ambiente natural e sob os cuidados de um educador discreto. $\mathrm{O}$ mestre, com efeito, não deve ensinar ninguém de modo direto, mas limitar-se a facilitar o desenvolvimento espontâneo do aluno. Assim, estimulando a instintiva curiosidade em relação aos fenômenos naturais, o educador conseguirá transmitir pensamento cientifico sem destruir a natural bondade do jovem, que progredirá, inclusive sob o ponto de vista ético, simplesmente refletindo sobre suas próprias experiências.

A educação transcorre progressivamente, de tal forma que cada estágio do processo pedagógico é adaptado às necessidades individuais do desenvolvimento. A primeira etapa é inteiramente dedicada ao aperfeiçoamento dos órgãos dos sentidos, pois as necessidades iniciais da criança são principalmente físicas. Incapaz de abstrações, o educando deve ser orientado no sentido do conhecimento do mundo através do contato com as próprias coisas. "A educação primeira deve, portanto ser puramente negativa. Ela consiste, não em ensinar a virtude ou a verdade, mas em preservar o coração do vício e o espírito do erro" (ROUSSEAU, 1995, p. 80).

Respeitando o estágio do nascimento aos doze anos de idade, é preciso enfatizar o exercício inteligente dos sentidos. Seguindo as sugestões do seu contemporâneo e amigo abade 
de Condillac ${ }^{6}$, Rousseau (1995, p. 120) escreve: As primeiras faculdades que se formam e se aperfeiçoam em nós são os sentidos, que, portanto, deveriam ser cultivados em primeiro lugar, mas que, ao contrário, são esquecidos on inteiramente relegados. Exercitar os sentidos não quer dizer somente usá-los, mas aprender a julgar bem através deles, ou seja, por assim dizer, aprender a sentir, porque não sabemos tocar, nem ver, nem ouvir senão no modo pelo qual aprendemos.

Daí a reivindicação de educar a criança a desenvolver livremente a necessidade de moverse, de brincar e de tomar posse de seu próprio corpo. Segundo Soëtard (2010, p.25) tanto os partidários da não intervenção do adulto, como por exemplo, o escocês A. S. Neil da Escola de Summerhill fundada em 1921, assim como aqueles que apenas facilitam o desenvolvimento do desejo natural de aprender da criança, em alguns momentos, podem se apoiar no princípio da educação negativa que “[...] segundo a qual o mestre é chamado a "fazer tudo sem fazer nada" e "dar à criança o desejo de aprender", sendo-lhe bom qualquer método" (SOËTARD 2010, p.25).

A educação negativa é a idéia-guia da pedagogia de Rousseau, segundo a qual se aprende por si mesmo. O educador, portanto, não deve transmitir nenhum saber, todavia - e esta é a leitura mais correta da obra - deve evitar que o aluno entre em contato com as perniciosas influências morais da sociedade humana; satisfazer sistematicamente a sua natural

\footnotetext{
${ }^{6}$ Étienne Bonnot, que depois se tornou abade de Condillac, nasceu em Grenoble, em 1714. Sua primeira obra relevante foi o Ensaio sobre a Origem dos Conhecimentos Humanos, publicada em 1746 que tinha como objetivo o estudo do espírito humano, não para descobrir sua
}

curiosidade em qualquer âmbito; predispor situações da vida adequadas a favorecer seu crescimento espontâneo. Por isso é chamada de negativa, por não trabalhar a imposição de normas e conteúdos, e focar-se em coibir o contato com ideias perniciosas.

$\mathrm{Na}$ visão do filósofo genebrino isto liberta o aprendiz da tirania das opiniões humanas; a criança, por si mesma, e sem nenhum esforço especial, identifica-se com as necessidades de sua vida imediata e torna-se auto-suficiente. Vivendo fora do tempo, anda precisando das coisas artificiais e não encontrando qualquer desproporção entre desejo e capacidade, vontade e poder, sua existência vê-se livre de toda ansiedade com relação ao futuro e não é atormentada pelas preocupações que fazem o homem adulto civilizado viver fora de si mesmo.

É necessário, entretanto, prepará-la para o futuro. Isso porque ela tem uma enorme potencialidade, não aproveitada imediatamente. A tarefa do educador consiste em reter pura e intacta essa energia até o momento propício. Nesse sentido, é particularmente importante evitar a excitação precoce da imaginação, porque esta pode tornar-se uma fonte de infelicidade futura. Outros cuidados devem ser tomados com o mesmo objetivo e todos eles podem ser alcançados ensinando-se a lição da utilidade das

natureza, mas para conhecer suas operações, estudar de que modo elas se desenvolvem e como devemos executá-las a fim de adquirir todo o conhecimento de que somos capazes. Ele morreu em 1780. (REALE; ANTISIERI, 2005, PP. 245-246) 
coisas, ou seja, desenvolvendo-se as faculdades da criança apenas naquilo que possa depois serlhe útil.

Nesse sentido, a educação torna-se o caminho para a sociedade renovada, com todo o seu rigor e a sua expansão social, bloqueando no berço toda forma de egoísmo, bem como toda forma de ansiedade pelo futuro, que apaga a alegria do presente. A certeza de uma sociedade harmônica, dominada pela vontade geral, evita os falsos sentimentos provocados por uma sociedade competitiva, e nos convoca a desfrutar o presente e toda situação, livres dos temores e dos fantasmas do imaginário de um futuro competitivo e conflitante.

\section{Considerações Finais}

A progressividade educacional preconizada por Rousseau é - sintetizando o conceito por ele estabelecido de educação - um processo adaptado às necessidades individuais do desenvolvimento, com etapas dedicadas ao aperfeiçoamento dos sentidos enquanto as necessidades das crianças forem físicas, passando ao momento em que o educando começa a ser orientado sobre o conhecimento do mundo através do contato com ele. O filósofo genebrino tende a apresentar na obra em análise, um processo educacional não diretivo, nem intervencionista, porém, muito longe de não ser subjetivo, em face de sua contaminação ora pela intervenção do mestre e ora pelo contato com o ambiente social.

Desta forma, uma dúvida que nos surge é se a "educação negativa" preconizada por Rousseau não reforçaria o que podemos chamar de "desnaturalização" do desejo pelas instituições sociais, como a escola por exemplo. Pois, ser educado da forma que ele desenha em uma sociedade como a nossa, permeada por uma diversidade de valores, idéias e comportamentos; muitas das vezes conflitantes entre si, nos lembra Georges Sniders (apud SOËTARD 2010, p.25): [...] seria uma ilusão deixar a criança à sua própria espontaneidade, porque o que se exprimiria nela não seria jamais a natureza, mas um conjunto das influências não criticadas e não corrigidas que a recobrem.

Adicionalmente, aproveitando-se do exemplo da escola, destacamos que Boto (2010, p. 287) enfatiza que o fenômeno da secularização na educação é um dos alicerces do iluminismo e da própria modernidade e que ao mesmo tempo em que ocorre a secularização das instituições, também é notada uma racionalização dos costumes.

No entanto, em defesa de Rousseau pesa o fato de que apesar de ser um iluminista e jusnaturalista, ele se oponha aos seus contemporâneos, pois estes consideravam já encaminhado o itinerário da libertação, à medida que o filósofo genebrino via uma sociedade ainda em processo de decadência e superstição e por isso pregava uma reforma na educação. 
Rousseau (1995, p. 211) defendia ainda a convivência em sociedade considerando que: "[...] um homem que se quisesse olhar como um ser isolado, não atendendo a nada e bastando-se a si mesmo, só poderia ser um miserável". Examinando mais detidamente o romance pedagógico Emílio, fica claro que (REALE; ANTISIERI, 2005, p. 287) o princípio-chave da liberdade não é, em momento algum, caprichoso e desordenado, e sim constitui uma liberdade bem orientada. Ressaltamos que ele era leitor de Platão e tecia elogios a sua obra, $A$ República, a qual considerava um grande tratado sobre educação. Desta forma, examinando detidamente, enxergaremos no preceptor de Emílio, o legislador de Platão, "aquele que vê além, que representa o retorno à caverna metaforizado por Platão" (PONTES, 2013, p. 55), um orientador para um ensino reflexivo sobre a sociedade, que visa o bem próprio e do outro.

A educação preconizada por Rousseau na Obra Emílio on Da Educação é primordialmente negativa, pois se baseia em uma intervenção sobre aquilo que não deve ser feito e, essencialmente subjetiva quando pensamos nas formas de intervir. Aliás, Russel (1945, p. 494) aponta o subjetivismo como uma característica marcante desse filósofo que, juntamente com o movimento romancista do século XVIII, estendeu esta doutrina filosófica da teoria do conhecimento para a ética e a política.

Desta forma, devemos considerar pela leitura da obra e o conhecimento do autor que a realidade do mundo objetivo depende das características, formas e explicações que lhe são atribuídas pela subjetividade humana. Emílio (a criança) primeiramente, vai se apropriar - direta ou indiretamente - desta realidade, fator preponderante para o seu processo cognitivo. Sendo que, um processo educacional reflexivo deve iniciar-se quando a criança adquire consciência de suas relações com os semelhantes e com o mundo. Passa-se, então, do terreno da pedagogia propriamente dita aos domínios da teoria da sociedade e da organização política. E é justamente a este segundo momento que estão ligadas as disciplinas de filosofia e sociologia, que devem proporcionar reflexões sobre $\mathrm{o}$ homem e a sociedade.

A reflexão é uma forma de aprendizado defendida também por Montaigne, Filósofo do século XVI, que dedicou uma parte da obra Ensaios a educação das crianças. Assim como Rousseau, ele pensava a educação de forma muito mais natural e reflexiva, aconselhando (MONTAIGNE, 1972, p. 82) àqueles que, mesmo depois de refletirem sobre algo, não chegam a conclusão alguma a ficarem "na dúvida", pois, acrescenta ele, "só os loucos têm certeza absoluta $[\ldots] "$.

\section{Referências}

ASSIS, Machado de. A Sereníssima República. Rio de Janeiro: Nova Aguilar, 1994. Disponível em: 
<http://www.dominiopublico.gov.br/downloa

d/texto/bv000239.pdf>. Acesso em: 26 nov. 2014.

BOTO, Carlota. A invenção do Emílio como conjectura: opção metodológica da escrita de Rousseau. Educ. Pesqui., São Paulo, v. 36, n. 1, Apr. 2010 Disponível em: $<$ http://www.scielo.br/scielo.php?script=sci_ar ttext\&pid=S1517-97022010000100002\&lng $=$ en\&nrm=iso $>$. Acessado em: 24 Nov. 2014

GELAMO, Rodrigo Pelloso. $O$ ensino da filosofia no limiar da contemporaneidade : o que faz o filósofo quando seu ofício é ser professor de filosofia?. São Paulo: Cultura Acadêmica, 2009.

LAÊRTIOS, Diôgenes. Vidas e doutrinas dos filósofos ilustres. Trad. Mário da Gama. 2. Ed. Brasília: Editora Universidade de Brasília, 2008. MONTAIGNE, Michel de. Ensaios. Trad. Sérgio Millet. Col. Pensadores. São Paulo: Abril Cultural, 1972.

PONTES, Jorge Marques. A Importância do Legislador no Contrato Social. Augusto Guzzo Revista Acadêmica, São Paulo, n. 12, p. 45-56, dez. 2013. ISSN 2316-3852. Disponível em: $<$ http://www.fics.edu.br/index.php/augusto_g uzzo/article/view/166>. Acesso em: 26 Nov. 2014.

REALE, Giovanni. ANTISIERI, Dario. História da filosofia: de Spinoza a Kant. v. 4. São
Paulo: Paulus, 2005.

ROUSSEAU, Jean-jacques. Do contrato social: princípios do direito político. Trad. Agnes Cretella e José Cretella Júnior. São Paulo: Revista dos Tribunais, 2008.

ROUSSEAU, Jean-Jacques. Emílio ou Da Educação. 3.ed. Rio de Janeiro: Bertrand Brasil, 1995.

RUSSELL, Bertrand. A History of Western Philosophy: and its Connection with Political and Social Circumstances from the Earliest Times to the Present Day. New York: Simon and Schuster, 1945.

SOËTARD, Michel. Jean-Jacques Rousseau. Trad. Verone Lane Rodrigues de oliveira. Recife: Fundação Joaquim Nabuco, Editora Massangana, 2010. 